\title{
The case for the physician assistant
}

\author{
Nick Ross, Jim Parle, Phil Begg and David Kuhns
}

\begin{abstract}
The NHS is facing a crisis from the combination of EWTD, MMC, the ageing population and rising expectations; thus its tradition of high quality care is under pressure. Physician assistants (PAs) are a new profession to the UK, educated to nationally set standards and, working as dependent practitioners, provide care in the medical model. PAs are currently employed by over 20 hospital Trusts as well as in primary care. They offer greater continuity than locum doctors and at considerably lower cost. PAs maintain generic competence and can therefore be utilised as required across different clinical areas. The stability of PAs in the workforce will be an additional resource for junior doctors on brief rotations. For the full benefits of PAs to be realised, and for the safety of the public, statutory registration and prescribing rights are required. Active support from the NHS is now needed to develop the workforce required.
\end{abstract}

KEY WORDS: physician assistant, multidisciplinary team, EWTD, continuity of care

\section{Introduction}

The NHS is facing a multifaceted crisis of:

- service continuity for patients as the European Working Time Directive (EWTD) reduces individual doctor's hours

- education for doctors in training as a consequence of Modernising Medical Careers (MMC)

- resources, which are being squeezed by a relative reduction in funding and an increase in demand from an ageing population, increasing expectations and medical complexity.

To try to deal with this crisis, hospitals are spending increasingly large amounts on locum cover: $£ 767$ million in England alone in $2010,{ }^{1}$ which is an increase of more than $100 \%$ since the $2007-8$

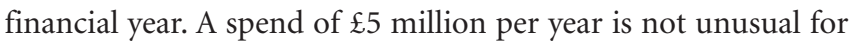
a 300-400 bed district general hospital. Although this maintains medical cover, it does not guarantee continuity or quality of service provision. ${ }^{2}$ The possibility of using a 'mid-level practitioner' to supplement the medical workforce has previously, and on more than one occasion, been discussed by the Royal College of Physicians (RCP)..$^{3-5}$ We strongly suggest that the time has now come to consider physician assistants as part of the solution

Nick Ross, ${ }^{1}$ professor in medical education; Jim Parle, ${ }^{1}$ professor of primary care; Phil Begg, ${ }^{2}$ associate dean for primary health care; David Kuhns, ${ }^{3}$ PA-C advisor to physician assistant programme

${ }^{1}$ University of Birmingham; ${ }^{2}$ University of Wolverhampton; ${ }^{3}$ University of Aberdeen to the crisis. As Farmer et al wrote in their recent report on a prospective trial of physician assistants in Scotland: ${ }^{6}$

'... [physician assistants are] moving from the USA to other parts of the world at this time expressly because [they] can meet the world's current health workforce gaps'.

\section{Background}

The role of the physician assistant was developed in its modern form in the USA in the 1960s with the aim of meeting the needs of underserved populations. The profession has expanded from very small beginnings in the 1960 s, and more than 4,500 physician assistants now graduate every year from more than 150 schools (including institutions such as Yale University and George Washington University in the USA, and McMaster University in Canada). About 81,000 physician assistants are working in practice in the USA ${ }^{7}$ - around one-tenth of the number of practising doctors. The profession has also expanded into every clinical field of medicine in the USA: from family practice to intensive care; from local general hospitals to internationally renowned centres of excellence, such as Johns Hopkins University, Cleveland Clinic and Mayo Clinic; and from public hospitals that provide Medicaid-funded care to the White House medical team.

Although the profession in the USA has matured to the point where it has separate organisations for practising physician assistants, education of physician assistants, licensing of programmes and certification of physician assistants, it has never sought to dilute the partnership between physician assistants and their supervising clinicians. The ethos of working to the medical model and to a named medical supervisor (ie as a dependent rather than an autonomous practitioner) is instilled into every student and remains central to the broader philosophy of physician assistants.

This philosophy has also moulded the development of the profession in the UK. The first physician assistants were 'imported' from the USA in 2003 to work in underserved primary care practices in the West Midlands. It was clear that the concept translated well into the NHS, which led to a grassroots push to train physician assistants in the UK. This interest was paralleled in the Department of Health, with its exploration of 'new ways of working. This resulted in funding for the development of the Competence and curriculum framework for the physician assistant $t^{8}$ by a steering group chaired jointly by the RCP and Royal College of General Practitioners (RCGP). The document defined a physician assistant as: ${ }^{8}$

'a new healthcare professional who, while not a doctor, works to the medical model, with the attitudes, skills and 
Table 1. Total of trusts currently employing physician assistants.

\begin{tabular}{|c|c|c|}
\hline Trust* & Hospital & Clinical areas \\
\hline \multicolumn{3}{|l|}{ Scotland } \\
\hline National Waiting Times Centre & Golden Jubilee National Hospital & - Cardiology \\
\hline NHS Lanarkshire & Hairmyres Hospital & $\begin{array}{l}\text { - Surgical internship } \\
\text { - Orthopaedics } \\
\text { - Emergency department } \\
\text { - Vascular surgery } \\
\text { - General surgery }\end{array}$ \\
\hline Lothian University Hospitals & Lothian & - Oncology \\
\hline \multicolumn{3}{|l|}{ Midlands } \\
\hline Dudley Group of Hospitals & Russells Hall Hospital & - Emergency department \\
\hline George Eliot Hospital & George Eliot Hospital & $\begin{array}{l}\text { - Acute medical unit } \\
\text { - General medicine }\end{array}$ \\
\hline Sandwell and West Birmingham & City Hospital & - Emergency department \\
\hline Solihull and Birmingham Mental Health & Various sites & $\begin{array}{l}\text { - Mental health, including subspecialties: mother and } \\
\text { baby, liaison psychiatry and female forensic psychiatry }\end{array}$ \\
\hline Mid Staffordshire & Stafford & $\begin{array}{l}\text { - Emergency department } \\
\text { - Cardiology }\end{array}$ \\
\hline University Hospitals Birmingham & Queen Elizabeth Hospital & $\begin{array}{l}\text { - Neurosurgery } \\
\text { - Clinical decision unit } \\
\text { - Cardiology } \\
\text { - Acute medicine }\end{array}$ \\
\hline University Hospitals of Leicester & Leicester Royal Infirmary & $\begin{array}{l}\text { - Emergency department } \\
\text { - Elderly care } \\
\text { - Neurology } \\
\text { - Orthogeriatrics }\end{array}$ \\
\hline Walsall Healthcare & Manor Hospital & - Emergency department \\
\hline Heart of England Foundation Trust & Heartlands Hospital & $\begin{array}{l}\text { - Paediatrics } \\
\text { - Cardiology }\end{array}$ \\
\hline \multicolumn{3}{|l|}{ South } \\
\hline Barnet and Chase Farm Hospitals & Chase Farm Hospital & - Cardiology \\
\hline Buckinghamshire Healthcare & Stoke Mandeville & - Orthopaedics \\
\hline Epsom and St Helier University Hospitals & & $\begin{array}{l}\text { - Acute medical unit } \\
\text { - Respiratory medicine }\end{array}$ \\
\hline Great Western Hospitals & Swindon Hospital & $\begin{array}{l}\text { - Trauma and orthopaedics } \\
\text { - Acute medical unit } \\
\text { - Emergency department }\end{array}$ \\
\hline Kingston Hospitals & Kingston Hospital & - Emergency department \\
\hline North West London Hospitals & Northwick Park & - Emergency department \\
\hline Royal National Orthopaedic Hospital & Royal National Orthopaedic Hospital & - Spinal Injury \\
\hline
\end{tabular}




\section{Table 1. Continued.}

St Georges Healthcare

Weston Area Health

Epsom \& St Helier University Hospitals
St George's Hospital

Weston General

St Helier Hospital

Epsom Hospital
- Paediatric intensive care unit

- Oncology

- Gastrointestinal

- Acute medical unit

- Plastics

- Trauma and orthopaedics

- Vascular surgery

- Paediatric surgery

- Ear, nose and throat

- Urology

- Respiratory

- Emergency department

- Acute medicine

- Respiratory

- MAU

- Respiratory

*In addition, three Trusts are drawing up job descriptions for posts or are already advertising posts: Bedford General Hospital - general medicine posts; Shrewsbury and Telford Hospitals - posts in all areas; Mid Yorkshire Hospitals NHS Trust - general surgery posts at Pinderfields Hospital. Furthermore, Derby is considering employing physician assistants for the emergency and paediatric departments, and Northamptonshire is also considering employing physician assistants.

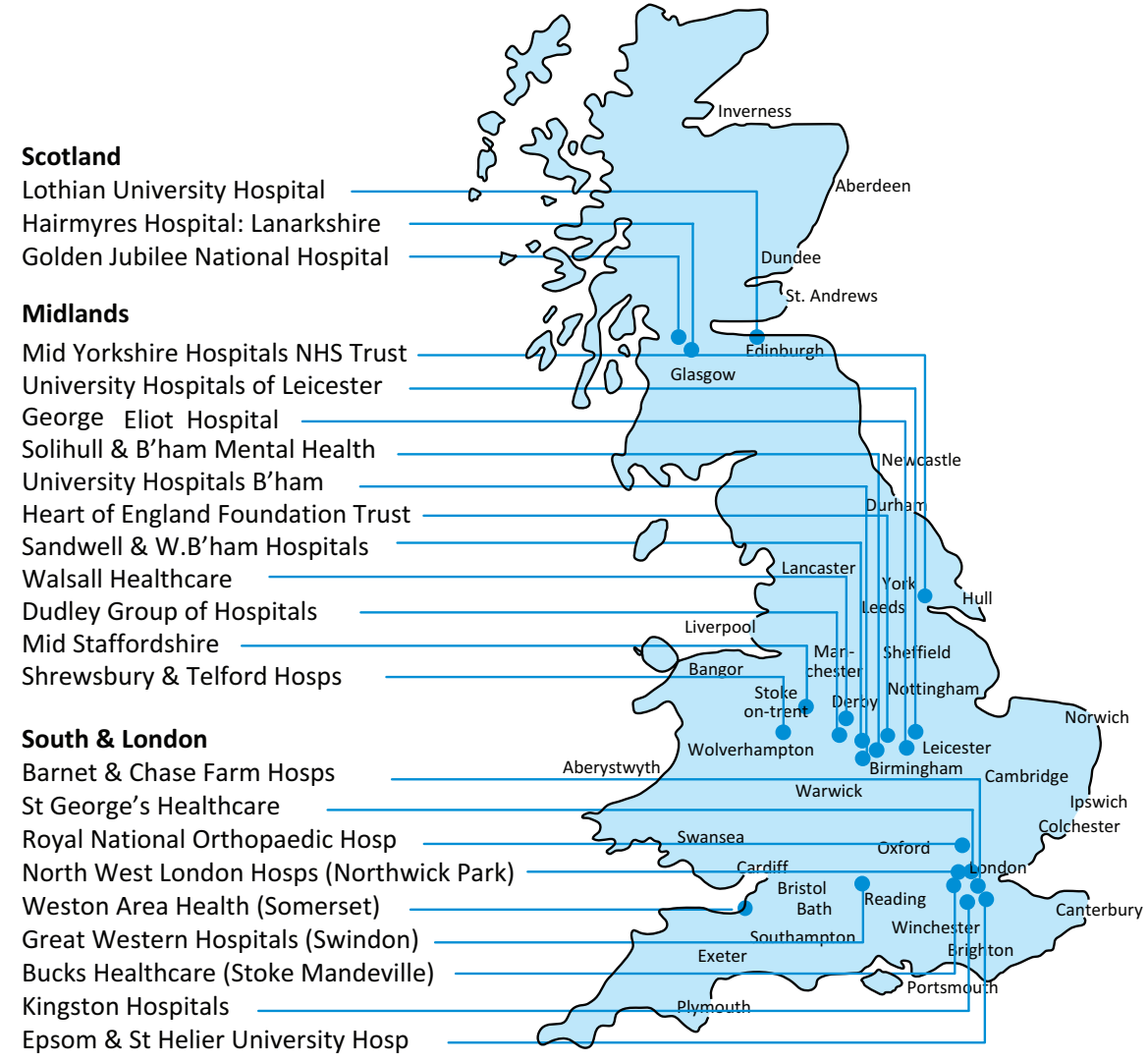

Fig 1. Physician assistant posts in hospitals in the UK.

knowledge base to deliver holistic care and treatment within the general medical and/or general practice team under defined levels of supervision?
The educational standard was set as a two-year postgraduate diploma programme split equally between theory and clinical practice, with students having to pass both their institutional assessment and a national examination of knowledge and skills in order to qualify. To date, about 130 students have qualified from programmes in the UK, with almost all employed as physician assistants in a wide range of specialties across 21 hospital trusts, as well as in primary care (Table 1, Fig 1).

\section{Benefits of physician assistants for the clinical team}

Consultants have reported significant loss of continuity for patient care as a result of the EWTD and MMC. ${ }^{9}$ As physician assistants can be anticipated to stay in post for some years (an average of 9.4 years in the USA), ${ }^{10}$ they will be able to develop collegiate understanding and day-to-day familiarity with how individual medical teams and multidisciplinary teams (MDTs) work. In the consultant-led service described by Temple, ${ }^{11}$ they could provide a stable element in a continually changing medical workforce. The relationship between supervising consultant and physician assistant is based on trust and mutual respect, and the scope of practice of the physician assistant is determined by mutual negotiation and develops over time. ${ }^{12}$ Physician assistants 


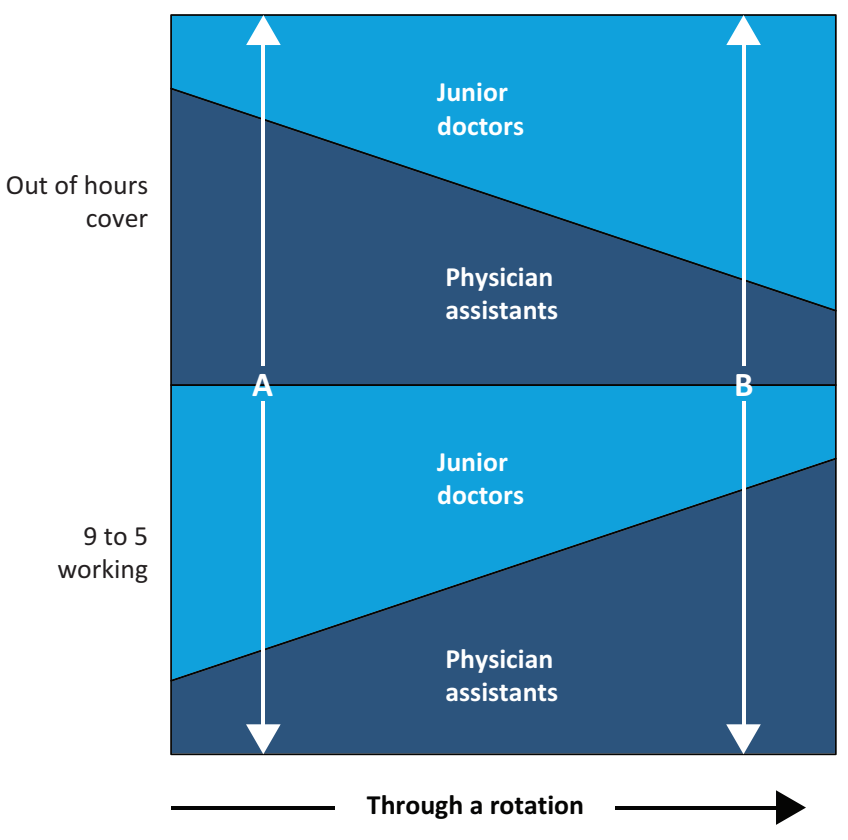

Fig 2. Varying role of the physician assistant within a medical team. Early in a trainee's rotation (point A), physician assistants might provide more of the out-of-hours cover but spend sufficient time working with the foundation doctor during the day to help support their development. Once the foundation doctor is more familiar with the unit (point B), they will be able to provide (and learn by providing) a greater proportion of the out-of-hours cover.

provide long-term stability that benefits both the consultant and the junior doctors within a consultant-led service. One of the benefits of the physician assistant model is that, rather like the utility player in a football team, the physician assistant can fulfil different roles depending on team needs. Experience shows that physician assistants provide 'the glue' for the MDT, linking nursing, medicine and other professions while staying focussed on the patient.

Clinical teams are varied and increasingly specialised. Because of their training and re-certification (see below) the physician assistant can provide the broader medical perspective that some clinical teams may have lost as a consequence of hyperspecialisation. Although physician assistants will clearly develop expertise in the area in which they are working, maintaining a broad clinical perspective remains central to the profession.

\section{What might a medical team that included physician assistants look like?}

Because of the difficulty of managing medical cover in a way that meets EWTD and MMC requirements, the firm structure that served the NHS so well is largely a thing of the past. We would propose that, given time to develop the professional resource, physician assistants could enable a new, stable firm structure to be established. Such a firm structure might, for example, consist of two consultants, a senior specialist trainee, a junior specialist trainee, two foundation doctors and a number of mid-level practitioners, including physician assistants. The training needs of junior doctors and their capacity to meet the firm's service commitments will vary both in the longer term (eg a senior trainee gaining promotion) and in the short term (over the length of a foundation year rotation) (Fig 2). The physician assistants, as a stable element within the team, could vary their shifts over time to provide support for trainees during the day and out-of-hours cover as appropriate to the situation.

\section{Benefits to the institution}

Employing physician assistants as an integral part of the medical and wider healthcare teams provides significant benefits for institutions. As with any other new component of the workforce, a bedding-in period is necessary, but, once established, physician assistants have an excellent track record as team players. ${ }^{6}$ The career path for a physician assistant, which involves far less frequent job moves than, for example, that of junior doctors, makes the bedding-in time a worthwhile investment for the institution, as well as the healthcare team, and reduces human resources' workload in terms of advertising and appointing to posts.

The loss of the firm structure and changes to shift patterns means that the management and governance of medical care is often more complex than was previously the case. Lack of continuity and the increased risk of medical error in such circumstances increase the exposure of healthcare provider institutions to litigation. This is exacerbated by the necessity for Trusts to employ locum doctors, which, as noted in our introduction, constitutes a massive drain on limited NHS budgets. Increasingly, locums are covering not just short-term sickness but posts that are being held empty or cannot be filled. The costs might be justifiable if the use of locums maintain the continuity and quality of care; however, whatever the quality of individual locums, evidence suggests that, considering the locum workforce as a whole, variability of standards, lack of knowledge of specific clinical and institutional contexts, and limited personal and professional investment results in a reduction in professional and patient satisfaction. ${ }^{2}$

Physician assistants, on the other hand, will have the organisational knowledge and commitment that locums may lack. In established posts, they provide day-to-day stability and continuity within the clinical team. Because of their broad clinical training and generalist periodic re-certification, they also offer the organisation a flexibility that medical locums (or trainees) cannot, enabling their deployment across a number of units to cover periods of sickness and, in the longer term, their redeployment when service needs change. Because of salary levels, institutions would be in a position to employ two full-time physician assistants for the cost of a full-time equivalent locum. Trusts may wish to consider top-slicing the locum budget to pay for a cadre of physician assistants to work flexibly across all clinical areas.

Whether employed as a long-term member of a particular medical team, which we would suggest offers the greatest benefits to patient and fellow professionals, or as part of a pool to be deployed to meet service needs, the physician assistant offers the institution a cost-effective means of managing care, with greater 
confidence about quality and with improved and simplified governance.

\section{Why physician assistants rather than advanced nurse practitioners?}

Although there is more than enough work to occupy both physician assistants and advanced nurse practitioners, there are significant differences. Advanced nurse practitioners regard themselves as autonomous rather than dependent professionals and would not consider themselves as part of a medical team, as opposed to the MDT. Although many advanced nurse practitioners fulfil roles previously restricted to doctors rather than those traditionally associated with nursing, and do so very well, they are 'advanced' within a particular clinical field. Their specialism is a huge strength within that field but also means that, in contrast with physician assistants, they lack both the broader medical perspective that is of such value to the specialist medical team and the workforce flexibility needed by healthcare institutions. In addition, there is no set national standard for advanced nurse practitioners and they generally are not trained in the medical model as diagnosticians. This often leads to an individual consultant developing local roles that are not transferable between NHS organisations, and that thus impacts on longer term job satisfaction. Advanced nurse practitioners presently score heavily over physician assistants because, as registered professionals, they can be given independent prescribing rights, which leads to the next question...

\section{What about statutory registration for physician assistants?}

When the Competence and curriculum framework for the physician assistant was published in 2006, it was a clearly stated intention that the profession should move rapidly towards statutory registration. However, the current government has decided that no more professions will be given statutory registered status and has instead offered the development of an assured voluntary register. ${ }^{13}$ As there is already a managed voluntary register for physician assistants, ${ }^{14}$ it is not yet clear what further protection the assured voluntary register will offer the public. Prescribing is a core part of the physician assistant's role in the USA, and although physician assistants in the UK are trained in prescribing, they can currently only propose medication for sign off by a doctor. Although it is possible to manage governance in this way, it is far from ideal. We suggest that the government will be faced with a choice of either allowing prescribing rights for appropriately trained professions on an assured voluntary register or allowing statutory registration for professions in which prescribing is an appropriate part of the role.

\section{What about standards?}

Among clinical professions in the UK, physician assistants are unique in having not only a nationally agreed curriculum frame- work ${ }^{9}$ but also both a national assessment and re-certification process. Universities in the UK have collaborated to establish standards for entry to the profession, a knowledge test comprising 200 single-best-answer, multiple-choice questions and a 16-station objective structured clinical examination (OSCE). This approach is modelled on the system in the USA and ensures that students achieve the same standard whichever university they attend. In addition, the knowledge test over the last two years has been based largely on questions derived from the question bank used for the American national examinations (run by the National Commission on Certification of Physician Assistants) ${ }^{15}$ and we have shown that students in the UK (and from the physician assistant course in Queensland, Australia) have achieved a similar standard of knowledge to that achieved by students in the USA. ${ }^{16}$ In addition, in collaboration with the UK Association of Physician Assistants, universities in the UK have committed to providing a test of general medical knowledge that physicians will take every six years to obtain re-certification.

\section{Won't physician assistants reduce medical employment and training opportunities?}

Concern has been expressed that, in a shrinking NHS, physician assistants will be employed at the expense of doctors. As we have argued above, there is ample scope for the employment of physician assistants as a replacement for locum cover without affecting medical training jobs or permanent positions. Junior doctors, most of whom will not have worked with physician assistants (for the views of one who has, see Goudie), ${ }^{17}$ have suggested that meeting the training needs of physician assistants will reduce training available to junior doctors in an NHS in which training opportunities are limited. The evidence supports our view that physician assistants, as stable members of medical teams, will actually provide an additional training resource for junior doctors on rotation. ${ }^{6,18}$ They are able to provide information about organisational policy and consultant preferences, as well as training, observation and feedback in relation to practical aspects of clinical work (Fig 3).

\section{Are physician assistants available?}

Currently, demand from hospitals and primary care is in danger of outstripping the number of trained physician assistants available in the UK. Although there will be benefits to hospitals able to employ a mix of relatively newly qualified physician assistants in the UK and more experienced physicians from the USA, a strategy needs to be put in place to increase the number of training places in the UK and to enable suitable candidates to enter postgraduate physician assistant studies, which, unlike postgraduate entry to medicine, are currently not covered by the graduate tax proposals. Much of the groundwork for the physician assistant initiative has already been done and the project is readily scalable. The Competence and curriculum framework for the physician assistant provides the basic skeleton for any 


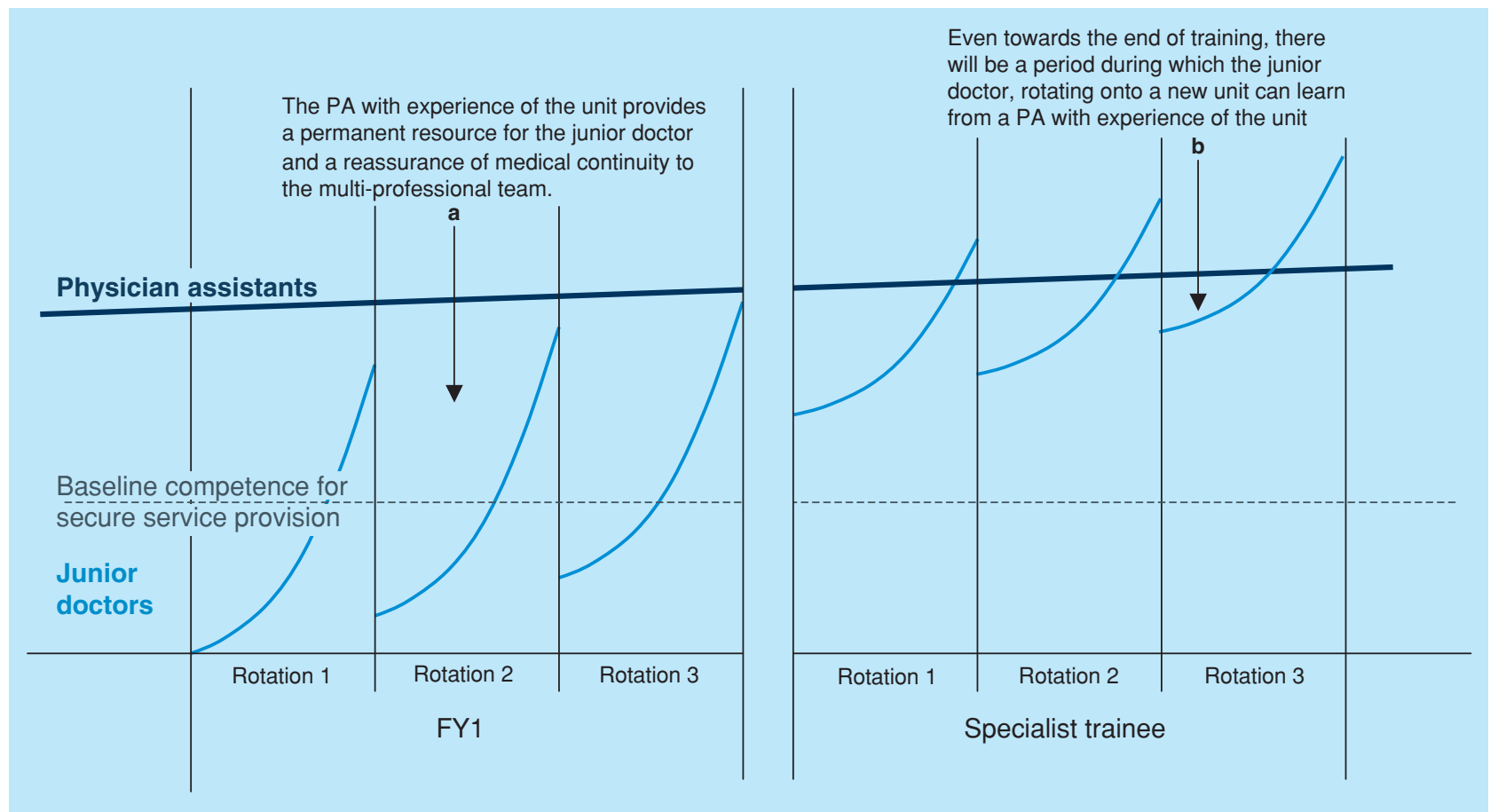

Fig 3. Supportive role of physician assistants for trainee doctors. Junior doctors develop competence in each rotation. Some clinical learning is generic and at the beginning of the next rotation they do not start from square one, but they do need to develop knowledge of a new specialist area from scratch. During foundation year 1 (FY1), even at the peak of their competence in a unit, junior doctors will not reach the level of competence of an experienced physician assistant. Later in training they may still take some time in any rotation before their unit-specific knowledge is higher than that of the physician assistant.

university wishing to start a programme, and there is a wealth of experience (and a will for collaboration) among existing programmes. ${ }^{19}$ The national assessment ensures that all physician assistants from existing and new programmes meet common standards, and with so many hospitals already employing physician assistants in a wide range of roles, there are ready-made job descriptions to draw upon. What is needed now is impetus and influence.

\section{Conclusion}

Because of current supply, physician assistants might not offer an immediate solution, but, for all of the reasons identified above, we would argue that now is the time to invest in expanding the profession so that it can meet the needs of the NHS over the coming decade. This will require employers, clinician supervisors and team leaders to actively make the argument to the government and care commissioners that physician assistants offer a realistic solution to a number of issues facing the NHS and are a resource that would be maximised through statutory registration and the granting of prescribing rights. Alongside any lobbying of government and negotiation with potential training organisations, it would be appropriate for NHS Trusts and clinicians to explore the concept of the new pattern for a stable firm structure suggested above, as well as other models using mid-level practitioners. To enable that con- versation to take place, ways to enable stakeholders from different fields and different trusts to share ideas about how such a medical firm might be made a reality and might work effectively as part of the broader multiprofessional team need to be sought.

\section{Acknowledgement}

We would like to acknowledge all those who have been involved in the physician assistant initiative in the UK, who have thereby contributed to the ideas expressed in this article. We wish to pay tribute to all the physician assistants in the USA who have shared their passion for the profession, their experience and their expertise, particularly Rachel Ditoro, PA-C who, at an early stage, was crucial to the progress of this project.

\section{References}

1 Royal College of Surgeons of England. Locum doctor costs in NHS trusts in England: results of a study from the Royal College of Surgeons of England, November 2010. London: RCS, 2010. www.rcseng.ac.uk/publications/ docs/locum-doctor-costs-in-nhs-trusts-in-england [Accessed 5 January 2012].

2 Isles C. How I tried to hire a locum. BMJ 2010;340:c1412.

3 Stewart A, Catanzaro R. Can physician assistants be effective in the UK? Clin Med 2005;5:344-8.

4 Royal College of Physicians. Skillmix and the hospital doctor: new roles for the healthcare workforce. Report of a working party. London: RCP, 2001. 
5 Armitage M, Shepherd S. A new professional in the healthcare workforce: role, training, assessment and regulation. Clin Med 2005;5: $311-4$.

6 Farmer J, Currie M, West C et al. Evaluation of physician assistants to NHS Scotland, final report 2009. Inverness: Centre for Rural Health, 2009. www.abdn.ac.uk/crh/uploads/files/PA\%20Final\%20report\%20 Jan\%2009\%20version\%205.pdf [Accessed 4 January 2012].

7 American Academy of Physician Assistants. The PA profession: quick facts. Alexandria: AAPA, 2012. www.aapa.org/the_pa_profession/ quick_facts.aspx [Accessed 9 January 2012].

8 Department of Health. The competence and curriculum framework for physician assistants. London: Stationery Office, 2006. www.dh.gov.uk/en/Publicationsandstatistics/Publications/ PublicationsPolicyAndGuidance/DH_4139317 [Accessed 3 April 2012].

9 Federation of the Royal Colleges of Physicians of the UK. Census of consultant physicians and medical registrars in the UK, 2010: data and commentary. London: Royal College of Physicians, 2011. www. rcplondon.ac.uk/sites/default/files/rcp-census-2010_0.pdf [Accessed 6 January 2012].

10 American Academy of Physician Assistants. National physician assistant census report: results from AAPA's 2009 census. Alexandria: AAPA, 2010. www.aapa.org/uploadedFiles/content/Common/Files/National_Final_ with_Graphics.pdf [Accessed 5 January 2012].

11 Temple J. Time for training: a review of the impact of the European Working Time Directive on the quality of training. London: Stationery Office, 2010. www.mee.nhs.uk/pdf/JCEWTD_Final\%20report.pdf [Accessed 3 April 2012].

12 American Academy of Physician Assistants. Professional ethics. Alexandria: AAPA, 2010. www.aapa.org/your_pa_career/becoming_a_ $\mathrm{pa} /$ resources/item.aspx?id $=1518$ \&terms $=$ code $\% 20$ of $\% 20$ ethics [Accessed 6 January 2012].
13 Department of Health. Enabling excellence: autonomy and accountability for health and social care staff. London: Stationery Office, 2011. www. dh.gov.uk/en/Publicationsandstatistics/Publications/ PublicationsPolicyAndGuidance/DH_124359 [Accessed 6 January 2012].

14 Physician Assistant Managed Voluntary Register. The Physician Assistant Managed Voluntary Register (PA MVR). London: Physician's Assistant Register, 2012. www.paregister.sgul.ac.uk [Accessed 6 January 2012].

15 National Commission on Certification of Physician Assistants website. www.nccpa.net/exams.aspx [Accessed 3 April 2012].

16 International Association for Medical Education. AMEE 2011 Abstract Book: 29-31 August 2011, Vienna, Austria. Dundee: AMEE, 2011. www. amee.org/documents/AMEE\%202011\%20Abstract\%20Book.pdf [Accessed 6 January 2012].

17 Goudie S. The physician assistant. London: BMJ Careers, 2010. http:// careers.bmj.com/careers/advice/view-article.html?id=20001023 [Accessed 8 January 2012].

18 Urbis. Evaluation of the Queensland physician's assistant pilot - final report. Sydney: Urbis, 2010. www.health.qld.gov.au/publications/pa_ eval_final.pdf [Accessed 3 April 2012].

19 UK \& Ireland Universities Board for Physician Assistant Education. www.ukiubpae.sgul.ac.uk.

Address for correspondence:

Professor Nick Ross, Education Unit,

College of Medical \& Dental Sciences,

University of Birmingham,

Edgbaston, Birmingham B15 2TT

Email: n.m.ross@bham.ac.uk

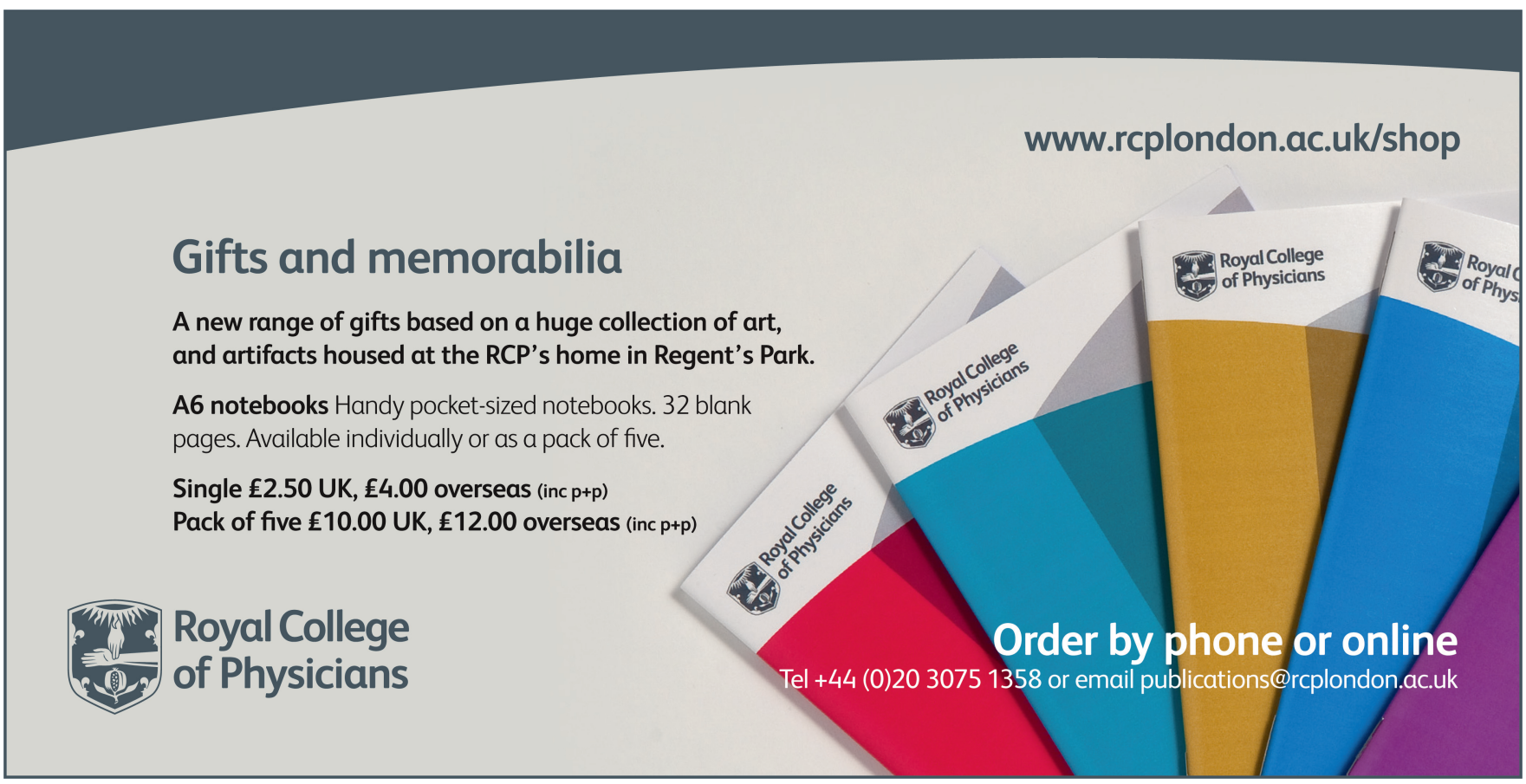

